\title{
A Review of Psychology of Science
}

\author{
Xi Yanhui ${ }^{1}$, Li Jianshan ${ }^{2}$ \\ ${ }^{1}$ Department of Sociology, Shandong University of Technology, Zibo, China \\ ${ }^{2}$ School of Philosophy, Nankai University, Tianjin, China
}

Email address:

xiyanhui1980@126.com (Xi Yanhui), lijianshan@126.com (Li Jianshan)

\section{To cite this article:}

Xi Yanhui, Li Jianshan. A Review of Psychology of Science. Psychology and Behavioral Sciences. Vol. 8, No. 6, 2019 , pp. $173-178$. doi: $10.11648 /$ j.pbs.20190806.15

Received: October 11, 2019; Accepted: December 19, 2019; Published: December 30, 2019

\begin{abstract}
As an important part of the metascience, psychology of science serves a crucial sector of the science research from the perspective of humanities and social science. In the 1930s, psychology of science began to sprout, but in the following decades psychology of science was relatively silent, with few iconic achievements, and was rarely valued. Since the 1970s, due to the outstanding contributions of Kuhn's paradigm theory, psychology of science has been widely recognized. Since the mid-1980s, psychology of science research has gradually brought together researchers and produced a series of important achievements. The discipline of psychology of science has been formally established. In general, the subjects of psychology of science mainly include psychology of scientific creation, social psychology of science, and psychology of scientist personality. In China, Wang Jisheng made pioneering contributions in the study of psychology of science in the mid-1980s, but psychology of science had few achievements in 1990s to the 2010s, and the results are also mainly concentrated on the scientific image. Since 2013, the research of psychology of science in Chinese have gradually increased, the theoretical discussion of psychology of science has increased, and the exploration of the autonomy has begun to show. All in all, the development of psychology of science still needs more scholars to join, and needs the recognition and attention of the academic community.
\end{abstract}

Keywords: Psychology of Science, Social Psychology of Science, China, Wang Jisheng

\section{Introduction}

Psychology of science is an important component of the metascience, which together with history of science, philosophy of science and sociology of science constitutes a basic metascience subject (Ziman's words). Kuhn first broadly legitimized psychological studies of science in the history of psychology of science. The true history of science can not be revealed completely without psychology of science [1]. D. K. Simonton also pointed out that the essence of science imagination will be incomprehensible if there's no psychological dimension [2]. It is also believed by Ziman that the sociological features of college science can only be understood through psychological terminology. Psychology of science is now at the edge of metascience research. But the more it is in this situation, the more it is necessary to review the history of psychology of science in order to better understand the overall outline of this subject.

\section{The Distinction Between Scientific Psychology and Psychology of Science}

There are two different kinds of "ke xue xin li xue" in the context of Chinese, one is scientific psychology in the field of psychology, and the other is psychology of science in the field of metascience.

\subsection{Scientific Psychology in the Field of Psychology}

Scientific psychology in the field of psychology is also known as scientism psychology, of which formation is related to the psychology's scientific pursuit. It was created in the imitation of the paradigm of natural science research. It was pursuing scientific methods, quantitative criteria, technical, and judging the value of psychological studies with scientific or not. Overtime, scientific has become the dominant ideology of psychology. Scientific psychology refers to the method of following the natural science approach strictly, taking a 
completely objective observation, experimental and statistical approach on the premise of value neutrality, achieving scientific by means of elemental theory, reductionism, atomism, etc. The most important for this kind of psychology is not problem, but method, and only method can be ensured the scientific.

\subsection{Psychology of Science from the Perspective of Metascience}

Psychology of science in the perspective of metascience is quite different from the scientific psychology. Psychology of science is a branch of the metascience, and it is a psychological research that directed at science. It mainly focuses on the creative thoughts of scientists, their cognitive and personality characteristics which are different from ordinary people. For nearly two decades, psychology of science has presented diverse research subjects and landscapes. In particular, social psychology of science research represents a new trend of this research.

\section{Psychology of Science: History and Subject}

\subsection{The Development of Psychology of Science}

Psychology of science has experienced a long period of silence since it was born. The existence of psychology of science as the sub-science was recognized as early as science of science was born in the end of 1930s, but there were few research in the next 20 years until 1950s. Wertheimer, a Gestalt psychologist, published the book "Creative Thinking" in 1959. In 1966, the humanistic psychologist Maslow published a monograph on The Psychology of Science. There are also some related papers during that period: (1) D. T. Campbell's "Blind variation and selective retention in creative thought as in other knowledge processes" published in Psychological Review in 1960. (2) R. C. Jacobs with D. T. Campbell's "The perpetuation of an arbitrary tradition through several generations of a laboratory microculture" published in the Journal of Abnormal and Social Psychology in 1961. (3) J. A. Chambers, published a paper in the Psychological Monographs: General and Applied named "Relating personality and biographical factors to scientific creativity".

1970 was a turning point for psychology of science which was mainly due to the success of Kuhn's influence. B. F. Singer published paper "Toward a psychology of science" in the American Psychologists. I. I. Mitroff published a paper entitled "The subjective side of science" in 1974. In 1976, M. J. Mahoney published "Scientist as subject: The psychological imperative". And R. Fisch's "Psychology of science" was published with J. Spiegel-Rosing and Price's "Science, Technology and Society: A Cross-disciplinary Perspective" in 1977.

In the 1980s, psychology of science research became popular gradually. Representative results before 1985 were: (1) S. C. Grover's "Toward a psychology of the scientist:
Implications of psychological research for contemporary philosophy of science" (1981). (2) R. D. Tweney, M. E. Doherty, \& C. R. Mynatt published "On scientific thinking" (Columbia University Press, 1981). (3) D. T. Campbell's "Experiments as arguments" published in E. R. House (Eds) Evaluation stuides review annual (1982). (4) "Historical distributions of multiple discoveries and theories of scientific change" published by A. Brannigan and R. A. Wanner in Social Studies of Science (1983). (5) Harvard University Professor Miller's "Image in Science Thinking" (1984), which emphasized the key role of image in science creation.

1986 was a key year in the history of psychology of science. In this year, psychology of science conference was held at the Memphis State University. The basic issues was discussed and the specialized research group was formed during the meeting. After that, many studies has emerged. Results are as follows: (1) D. Kulkarni and H. A. Simon's article "The processeses of scientific discovery: The strategy of experimentation", published in the journal of Cognitive Science (1988). (2) M. L. Frank and K. Richard's article "Psychology of the scientist: LVIII Anxiety about research: An initial examination of a multidimensional concept" published in the Psychological Reports (1988). (3)B. Gholson and A. C. Houts's article "Toward a cognitive psychology of science" published in Social Epistemology (1989). (4) A. Serchuk's article"What can the cognitive psychology of science bring to the science and technology studies?" (Social Epistemology, 1989). (5) W. R. Shadish and R. A. Neimeyer's article "Contributions of psychology to an integrative science studies: The shape of things to come", in The cognitive turn: Sociological and psychological perspectives on science, edited by S. Fuller, M. Demey, T. Shinn \& S. Woolgar (1989).

In 1989, a very representative collection of papers was published which is "Psychology of science: Contributions to metascience" edited by B. Gholson, W. R. Shadish, R. A. Neimeyer, and A. C. Houts (Cambridge University Press). It reviewed the history of psychology of science systematically, and developed a blueprint for its theoretical and practical research. In the essay, A. C. Houts wrote the article "Contributions for the psychology of science to metascience: A call for explorers". P. Barker wrote "The reflexivity problem in the psychology of science". In the 1990s, Shadish and Fuller's "The Sociel Psychology of Science" (Gilford Press, 1994) opened up a new direction in the study of psychology of science, marking a new perspective beyond cognition, personality and creativity. After 2000, G. J. Feist's book "The Psychology of Science and the Origins of the Scientific Mind" (Yale University Press, 2006) was published and became another masterpiece in the $21^{\text {st }}$ century. In addition, R. W. Proctor and E. J. Capaldi edited "Psychology of Science: Implicit and Explicit Processes", the research topics include: the role of the psychology of science and its methods, agency and reasoning in the psychology of science, implicit and explicit in the cognitive psychology of science, psychological influence on science, scientific creativity, unconventional perspectives on the conduct of sicence [3]. G. J. Feist and M. E. Gorman edited "Handbook of the Psychology of Science", 
this book explored: the foundation psychologies of science, the development and theory change of psychology of science, applied psychologies of science. This book also explored the creative genius in science; gender and science; conflicts, cooperation, and the competition in the field of science and technology; postmodernism and the development of the psychology of science; psychobiography and the psychology of science; the quantitative trends in the establishing a psychology of science [4].

Simonton has also made a prominent contribution to the study of psychology of science. He has wrote: "The Social Psychology of Creativity: An archival data Analysis" (1974), "Scientific Genius: A Psychology of Science" (1988), "Psychology, Science and History: An Introduction to Historiometry" (1990), "Origins of Genius: Darwinian Perspectives on Creativity" (1990). Simonton has also published more than 400 papers on scientific creativity and scientific genius.

\subsection{The Subject of Psychology of Science}

Different scholars have different understandings on the subject of psychology of science. In the book " The Psychology of Science and the Origins of the Scientific Mind" (2006), Feist divided it into biological psychology of science, developmental psychology of science, cognitive psychology of science, social psychology of science and applied psychology of science. Wang Jisheng has divided it into four aspects: creation psychology of science, management psychology of science, talent psychology of science and social psychology of science. According to the collation, here we will temporarily categorizes it into the following four aspects.

\subsubsection{Creative Thinking of Science}

Creative thinking of science is one of the most concerned topics in psychology of science. People often find the roots of scientific change in personal creation psychology. Wertheimer's "Creative Thinking", Campbell's "Blind variation and selective retention in creative thought as in other knowledge processes", Professor Miller's "Image in Scientific Thinking", and Simonton's "Origins of Genius" are all representative of such research. Campbell has proposed the hypothesis of creative thinking from the perspective of Darwinism (1960). More than 20 years later, Simonton inherited and enriched Campbell's point of view, arguing that Darwinian ideas can provide unique and valuable insights about the nature of creativity. The creative process from the perspective of natural selection follows two stages: blind change and selective retention. In the first stage, the creators' multiple vague ideas haven't produced ideas that dominate the situation yet. In the second, some concepts are chosen, others are excluded, the most appropriate concepts are preserved, and others tend to disappear [5]. Simonton interprets the blindness in the creative process as the process of creativity is implicit: first, it involves at least two complete concepts so that the selection can proceed; second, one of these changes is different from the other, with significant independent occurrence and survivability [6].

\subsubsection{Scientist's Creative Personality}

The creativity is an important problem in psychology of science. Merton pointed out that the study of scientific creative personality focuses on: the distinctive psychological qualities of creative geniuses in the scientific community, and the psychological process of preparing, gesturing, clarifying and confirming scientific thinking [7]. An important prerequisite for such research is to think of science as discoveries made by people with special research abilities. According to Maslow, science is the creation of man, it originated from human's motives, it is created, updated and supported by human beings. The research on the creative personality of scientists mainly focuses on the characteristics of scientists' differences in cognition, character and personality of ordinary people. Since the day psychology of science was born, researchers have been making efforts to portray or discover the qualities of this personality.

\subsubsection{Irrational Studies of Science}

The irrational research on science focuses on two dimensions: one is the study of the irrational factors on creativity, the other is the study on the existence psychological dimensions of scientists. Such research was primarily initiated by Maslow and developed in later social psychology of science (SPS). According to Maslow's view, the study of value, need and desire, the prejudice, the fear and interest must be a fundamental aspect of all scientific research. The cognitive exploration of scientists is linked to the need to alleviate their own anxiety and achieve cognitive coordination. The unknown object is probably the first thing that causes anxiety while the process of the exploration is the effort to calm down and reduce tension, vigilance and fear. Science can be seen as relatively defensive, stimulated by security needs, mainly driven by anxiety, acting in a way that alleviates anxiety [8]. What's more, the Merton's research on the ambivalence of scientists, the impedance of scientists also reveal the irrational psychological dimension.

\subsubsection{Social Psychology of Science}

Undoubtedly, social psychology of science belongs to the later research orientation, but it is expected to become a hot spot in the future. We can discover the impact of social dimensions on psychology of science through the proximity of sociology of science. According to Merton's view, we can discover the complex social psychological processes that affect scientific communication and scientific reward systems through the rationalized social structure research.

The creation of social psychology of science was in 1994. W. R. Shadish and S. Fuller published Social Psychology of Science in the same year. Social psychology of science in this book concerns: " 1 . Where do scientific ideas come from? 2. What factors play a role in the formation, revision, and persistence of scientific beliefs? 3. How are ideas disscussed throughout the scientific community? 4. Do we need to provide separate accounts for beliefs that are currently regarded as true versus those currently regarded as false?" [9] The theoretical resources that social psychology of science can be learned from social psychology are cognitive 
dissonance, attribution, authority obedience, attitude change, group pressure, herd, social cognition and social perception, prejudice, Rosenthal effect, experimenter effect of behavioral research, etc.

\section{The Characteristics of the Development of Psychology of Science}

Psychology of science has experienced a long period of isolation, and now it become institutionalized gradually. It has moved from a single creative thinking and personality research to a diversified subject.

\subsection{Three Stages of Psychology of Science}

Every subject area will go through three stages of isolation, identification and institutionalization in its process of development [10]. Psychology of science have experienced a period of more than 30 years of silence in the early stage. There was no significant influence and theoretical consciousness of psychology of science from 1930s to 1960s. 1970s was the beginning that psychology was recognized. People's attention on psychology of science had slowly aroused by Kuhn's emphasis on the psychological dimension. The research on psychology of science begun to increase and it gradually gained more recognition. In 1976, Mahoney's "Scientist as subject" was regarded as a classic of psychology of science research during that period, which demonstrated many defects in the process of science research, and questioned the extreme rationality successfully on description of science [11]. In the first half of $1980 \mathrm{~s}$, the research increased more than it in the 1970s.

Psychology of science began to become institutionalized in 1986. This year, the University of Memphis held an academic conference on psychology of science and established the Memphis group dedicated to psychology of science research. Since then, the subject of psychology of science began to become clearer, researchers began to review the history of psychology of science and explore its research topics. In 1989, the collection of "Psychology of Science" published by the Memphis Group discussed its systematic theory. Though the institutionalization of psychology of science was not mature at that time, the achievements it promoted had become increasingly apparent.

\subsection{The Topics of Psychology of Science: Characteristics and Its Changes}

\subsubsection{Permanent Subject: Studies on the Personality and Cognitive Characteristics of Scientists}

Psychology of science focused mainly on the cognitive characteristics and personality traits of individual scientists in the early times. Many people had a special interest in the intelligence, cognition, and personality of scientists beyond ordinary people before it was called the name "psychology of science". Such research became endless after it was born. In 1973, Eiduson and Beckman 's "Science as a Career Choice: Theoretical and Empirical studies" showed the results of various scientists' personality, demographics, and biological traits, which was compared with other people's traits. The implicit assumption of scientific creative research is that scientists have qualitative differences in intelligence, persistence, and diligence compared to others. But the problem is that the obvious difference is hardly agreed by people. Sociologists of science also found that careful empirical study of the personality traits of scientists did not provide a reliable knowledge to the ordinary people on the understanding of these issues [12].

\subsubsection{New Orientation: The Appearance of Social Psychology of Science (SPS)}

The appearance of social psychology of science is undoubtedly a necessary complement to the previous studies of scientific creative thinking and scientists' personality. Because of past cognitive and personality traits studies have focused on scientists as individuals, little attention has been paid to social interactions, roles and cultural factors that may have an impact on science. The birth of social psychology of science has made up for this deficiency. In the view of cognitive psychologist Tweney, SPS can show somethings that can be worked out by social psychology of science but could not be done by cognitive psychology of science. What makes social psychology of science different from most previous psychology of science studies is that it requires psychological analysis of the mixed explicit social elements.

\section{Psychology of Science Studies in China}

In general, the development of psychology of science in China is far from the disciplines of history of science, philosophy of science, sociology of science, ethics of science. The achievements of psychology of science in the 1980s were relatively large, in the 1990 s, psychology of science was at a low ebb, since 2000, the study of psychology of science has gradually taken on a new look. The studies of psychology of science in China mainly focused on three aspects: the general studies of psychology of science, the studies of scientific image and the psychological studies of scientific creation. Here we will mainly introduce the general research of psychology of science and scientific image.

\subsection{The Overall Studies of Psychology of Science}

The early research of Chinese psychology of science was mainly initiated by Mr. Wang Jisheng, Institute of psychology, Chinese Academy of Sciences. Mr. Wang Jisheng discussed psychology of science from seven aspects: intellectual factors and scientific creation; non-intellectual factors and scientific creation; the characteristics, requirements, types and methods of scientific creative psychology; inspiration, dreams and opportunities in scientific creation; group psychology of scientific creation; psychological problems of scientific and technological talents; the psychological problems in the reform of science and technology system [13]. In "Psychology of Scientific Creation" (1986), Mr. Wang Jisheng adopted the methods of psychological self-assessment and psychological 
investigation, more than 700 scientific and technological workers were studied quantitatively in the fields of scientific creative psychology and scientific management psychology. The topics include research on the development of intellectual and non-intellectual factors of scientists and technicians, quantitative study on the psychology of scientific and technological creation, quantitative study of science and technology management psychology, psychological health study of scientists and technicians.

In addation, Yan Bing (1985) translated the introduction of "Scientific Thinking" (edited by R. D. Twenne, M. E. Dougherty, C. R. Minat, 1981) named "the relationship between psychology of science and scientific research". The translation discussed the relationship between psychology of science and philosophy of science, the relationship between psychology of science and the history of science, the relationship between psychology of science and sociology of science, the research status of psychology of science at that time.

Since 2013, psychology of science research has shown an increasing trend. Kou Yu (2013) in her thesis "Psychology of science: A New Direction of Philosophy of Science", from the perspective of the history of scientific cognition and social psychology of science, this paper explored the possible path and value of psychology of science as a new direction of philosophy of science. Zhao Wanli etc. (2013) wrote "Cognitive disorders and balance strategies of scientists in paradigm shift period" which represents an attempt to explore the autonomy of Chinese psychology of science, represents a conscious exploration of social psychology of science. Wang Huaping (2014) proposed that "other research approaches in science theory, including historical, social, anthropological and even philosophical ones, should be incorporated into psychology of science, science theory should form a multi-disciplinary convergence pattern with psychology of science as its core" [14].

\subsection{Studies on Scientific Image}

The study of scientific image in China is mainly carried out by Li Jihong, Zhao Lingli and researchers who have relations with them. Researchers followed Miller's "Image in Scientific Thinking", which began in the early 1990s. Li Jihong (1997) mainly analyzed the case study of scientific images, such as Poincare's auditory images, Einstein's visual images, Heisenberg's mathematical adjustment images, and reveals the creative reasons of scientific images [15]. Li Jihong etc mainly discussed the concept of scientific image, the way of scientific image and related cases, the relationship between scientific image and scientific progress, the psychological mechanism analysis of scientific image, the case analysis of scientific discovery, and the cultivation of scientific image. Zhao Lingli (2007) directly regarded image as an organic combination of meaning and image which is an indispensable logical basis, processing method, procedure and result of creative activities [16].

\section{Conclusion}

Psychology of science has gone through more than 70 years from the germination to the conscious. For a long time, it was silent, did not make a significant impact, and failed to gain the true recognition. Since the end of the 1980s, it has gradually moved toward theoretical consciousness, and the quantity and quality of research have also greatly improved. After 1994, social psychology of science has become another new orientation in the study of psychology of science. Nowadays, there are still many problems in its own development process, such as lack of recognition and institutional identity, academic establishment is not fully established yet, academic exchange network needs to be expanded, and so on. In recent years, scholars outside the United States have also begun to pay attention to psychology of science. Chilean and Danish scholars reviewed the rise of cultural psychology of science, summarized that "cultural psychology of science proposes to understand the scientist as a purpose-oriented person that constructively transforms culturally available meanings in order to create novel scientific knowledge." [17] Peruvian scholar explored the early psychology thought of science in Paraguay, pointed out R. Ross who wrote an article in the Paraguayan journal "Letras" inó 1915 is the early explorer of psychology of science. Ross' argument is that geniuses' production is one of the most valuable potentials to a nation, "His argument agrees with considerations related to the subjective processes leading creative inspiration, the generation of new ideas and the relations between genius and insanity" [18]. These are all signs of the international development of psychology of science.

In China, psychology of science has not yet become a formal discipline. In the early days, the main researchers engaged in psychology of science are those majored in psychology, scientific management and dialectics of nature. In recent years, there have scholars majored in psychology, philosophy of science and technology \& sociology of science. In terms of research topics, early researchers mostly focused on the psychology of scientific creation, introduced incidentally the research of scientific research management psychology and scientific collective psychology. Since 2013, psychology of science has been showing professional exploration, marking the beginning of psychology of science. At present, there are still many limitations and deficiencies of Chinese psychology of science. First, this is due to the difficulty and complexity of psychology of science research itself. If one want engage in psychology of science research, he/she has to possess both the professional background of natural science and psychology, or the professional background of STS and psychology. However, there are few scholars who really have such conditions and prepare to commit themselves to psychology of science research in China. Second, it is due to the research community has not yet formed. In the 1980s, although Mr. Wang Jisheng made pioneering efforts in the study of psychology of science, it lacked the support of successors. Researchers were more 
concerning about the history of science, philosophy of science, ethics of science and sociology of science. However, psychology of science had not yet formed a research community.

\section{References}

[1] П. А. Рачков. Science of science: problem, structure, and basic principles. Han Bingcheng etc. translation. Peking: Science Press, 1984, p. 177.

[2] Quoted from Kou Yu. Psychology of science: a new direction of philosophy of science. Shandong University, 2013, pp. 17-18.

[3] R. W. Proctor, and E. J. Capaldi, Eds. Psychology of science: implicit and explicit processes. New York: Oxford University Press, 2012, contents.

[4] G. J. Feist, and M. E. Gorman, Eds. Handbook of the psychology of science. New York: Spring publishing company, 2013, contents.

[5] R. J. Sternberg, (2000). Books etcetera: Origins of genius by Dean K. Simmonton (Oxford University Press, 1999). Trends in Cognitive Sciences, 6, 246-247.

[6] S. Dasgupta. (2010). On the blind-mindedness of creative thought comment on "Creative thought as blind-variation and selective-retention: combinatorial models of exceptional creativity" by Dean Keith Simonton. Physics of Life Reviews, 2, 188-189.

[7] R. K. Merton, Sociology of science. Lu Xudong, Lin Ju Ren translation. Peking: Commercial Press. 2003, p. 515.
[8] A. H. Maslow. Psychology of science. Lin Fang translation. Kunming: Yunnan People's Publishing House. 1988, p. 19.

[9] W. R. Shadish, and F. Fuller, Eds. The social psychology of science. New York: The Guilford Press, 1994, p. 19.

[10] R. Glassman. Review Articles: Psychology of science/ theology of science: reaching out or narrowing? Journal of Religion and Science, 42 (3), 651-659.

[11] quoted from W. R. Shadish, and F. Fuller, Eds. The social psychology of science. New York: The Guilford Press, 1994, pp. 5-6.

[12] J. Ziman. An introduction to meta science. Liu Junjun, Zhang Ping and Meng Jianwei translation. Changsha: Hunan People's Publishing House. 1988, p. 246.

[13] Wang Jisheng. Psychology of science. Hangzhou: Zhejiang Education Press, 1986, preface p. 6.

[14] Wang Huaping (2014). The cognitive turn of scientific theory: toward psychology of science. Journal of Xuzhou Institute of Technology, 6, 21-28.

[15] Li Jihong, Yang Jianye, Li Xiaogang. Science image. Peking: Science Press, p. 129.

[16] Zhao Lingli. (2007). Artistic image, aesthetic image and scientific image: theoretic and empirical conception of the similarities and differences of psychological image of creative activities. Research on Dialectics of Nature, 7 104-110.

[17] D. Carré (2019). Towards a cultural psychology of science. Culture \& Psychology, Vol. 25 Issue 1, p3-32.

[18] José E. Garcia (2016). An Early Psychology of Science in Paraguay. Journal of Educational Psychology - Propósitos y Representaciones, v4 n2 p. 387-412. 